\title{
SEM Analysis of Ion Implanted SiC
}

\author{
Johan B Malherbe ${ }^{1}$, NG van der Berg ${ }^{1}$, AJ Botha ${ }^{1}$, E Friedland $^{1}$, TT Hlatshwayo ${ }^{1}$, \\ RJ Kuhudzai ${ }^{1}$, E Wendler ${ }^{2}$, W Wesch ${ }^{2}$, P Chakraborty ${ }^{3} \&$ EF da Silveira ${ }^{4}$ \\ ${ }^{1}$ D Department of Physics, University of Pretoria, Pretoria, 0002, South Africa \\ ${ }^{2}$ Institut für Festkörperphysik, Friedrich-Schiller-Universität, 07743 Jena, Germany \\ ${ }^{3}$ Saha Institute of Nuclear Physics, 1/AF Bidhannagar, Kolkata 700 064, India \\ ${ }^{4}$ Physics Department, Pontifícia Universidade Católica do Rio de Janeiro, Rio de Janeiro, Brazil \\ *Author for correspondence: johan.malherbe@up.ac.za
}

$\mathrm{SiC}$ is a material used in two future energy production technologies, firstly as a photovoltaic layer to harness the UV spectrum in high efficient power solar cells, and secondly as a diffusion barrier material for radioactive fission products in the fuel elements of the next generation of nuclear power plants. For both applications, there is an interest in the implantation of reactive and nonreactive ions into $\mathrm{SiC}$ and their effects on the properties of the $\mathrm{SiC}$. In this study $360 \mathrm{keV} \mathrm{Ag}^{+}, \mathrm{I}^{+}$ and $\mathrm{Xe}^{+}$ions were separately implanted into $6 \mathrm{H}-\mathrm{SiC}$ and in polycrystalline $\mathrm{SiC}$ at various substrate temperatures. The implanted samples were also annealed in vacuum at temperatures ranging from $900^{\circ} \mathrm{C}$ to $1600^{\circ} \mathrm{C}$ for various times. In recent years, there had been significant advances in scanning electron microscopy (SEM) with the introduction of an in-lens detector combined with field emission electron guns. This allows defects in solids, such as radiation damage created by the implanted ions, to be detected with SEM. Cross-sectional SEM images of $6 \mathrm{H}-\mathrm{SiC}$ wafers implanted with $360 \mathrm{keV} \mathrm{Ag}^{+}$ions at room temperature and at $600^{\circ} \mathrm{C}$ and then vacuum annealed at different temperatures revealed the implanted layers and their thicknesses. A similar result is shown of $360 \mathrm{keV} \mathrm{I} \mathrm{I}^{+}$ions implanted at $600^{\circ} \mathrm{C}$ into $6 \mathrm{H}-\mathrm{SiC}$ and annealed at $1600^{\circ} \mathrm{C}$. The $6 \mathrm{H}-\mathrm{SiC}$ is not amorphized but remained crystalline when implanting at $600^{\circ} \mathrm{C}$. There are differences in the microstructure of $6 \mathrm{H}-\mathrm{SiC}$ implanted with silver at the two temperatures as well as with reactive iodine ions. Voids (bubbles) are created in the implanted layers into which the precipitation of silver and iodine can occur after annealing of the samples. The crystallinity of the substrate via implantation temperature caused differences in the distribution and size of the voids. Implantation of xenon ions in polycrystalline $\mathrm{SiC}$ at $350^{\circ} \mathrm{C}$ does not amorphize the substrate as is the case with room temperature heavy ion bombardment. Subsequent annealing of the implanted polycrystalline samples leads to increased thermal etching effects such as grain boundary grooving. Damage due to channelling (or non-channelling) in the different crystallites resulted also in differences in thermal etching in the crystallites.

Keywords: Nuclear materials, photovoltaic materials, SiC, SEM, implantation, microstructure, voids, bubbles, defects, topography

\section{INTRODUCTION}

Traditionally, scanning electron microscopy (SEM) has been used to characterize the topography of surfaces before and after ion bombardment $[1,2]$. In recent years there had been significant advances in scanning electron microscopy (SEM) with the introduction of 
an in-lens detector. This allows SEM images to be taken with very low voltages, resulting in more surface sensitive images to be obtained. Another advantage with an in-lens detector system in SEM is that some defects can become visible. Twins and/or stacking faults which are normally only detected with transmission electron microscopy (TEM) can easily be seen on SiC using in-lens SEM [3,4].

Due to the Kyoto Protocol and global weather changes there is a demand to reduce the world's reliance on fossil fuel for power production. Consequently, many alternative power production technologies are being investigated. $\mathrm{SiC}$ is a material used in two future energy production technologies: As a photovoltaic layer to harness the UV spectrum in high efficient power solar cells, and as a diffusion barrier material for radioactive fission products in the fuel elements of the next generation of nuclear power plants.

For both applications, there is an interest in the implantation of reactive and non-reactive ions into $\mathrm{SiC}$ and their effects on the properties of the SiC. The semiconductor substrates of photovoltaic devices must be doped to create p-n junctions. In the case of $\mathrm{SiC}$, the doping is usually done via ion implantation and annealing. In nuclear reactors energetic heavy ions are produced during the fission reaction. These ions can cause radiation damage in the SiC leading to radiation-enhanced and radiation-induced diffusion, thereby defeating the purpose of the SiC as being a diffusion barrier for the radioactive fission products [5, 6]. Furthermore, these ions can also chemically react with the $\mathrm{SiC}$ destroying its integrity and its diffusion barrier properties.

In this paper, several examples of modern SEM investigations of such ion bombarded $\mathrm{SiC}$ surfaces before and after vacuum annealing are given. These investigations explain some of the properties resulting from such treatments.

\section{EXPERIMENTAL}

Single crystal $6 \mathrm{H}-\mathrm{SiC}$ (from Intrinsic Semiconductors ${ }^{\circledR}$ ) and polycrystalline SiC (from Valley Design Corporation ${ }^{\circledR}$ ) samples were investigated by field emission scanning electron microscopy (FEG-SEM) employing a Zeiss Ultra 55 instrument fitted with the usual SEM detectors and an in-lens detector. This instrument can be operated at voltages as low as $500 \mathrm{eV}$. In this study, we mostly employed $2 \mathrm{kV}$ in order to reduce the distorting effect on very low accelerating voltage SEM images of carbon build-up on the samples during electron beam exposure. With low accelerating voltages the sampling depth becomes smaller giving more representative picture of the morphology of the real surface. The in-lens detector gives SEM images which show defects present in the samples but at the expense of topographic detail which becomes more detectable with the normal SEM detector. In this paper only images taken in the in-lens mode are shown.

Some sample surfaces were prepared in the usual way TEM samples are prepared. The samples were glued together and cross-sectional samples were prepared by thinning and smoothing the samples by mechanical polishing. The final smoothing step for some of these samples were to bombard them with low energy $\mathrm{Ar}^{+}$ions at glancing angles while rocking the samples nearly perpendicular to the interface.

$360 \mathrm{keV} \mathrm{Ag}^{+}, \mathrm{I}^{+}$or $\mathrm{Xe}^{+}$ions were implanted at an incidence angle of $7^{\circ}$ to fluences of $2 \times 10^{16}$ $\mathrm{cm}^{-2}$. A dose rate of about $1 \times 10^{12} \mathrm{~cm}^{-2} \mathrm{~s}^{-1}$ was used. Notwithstanding this relatively low rate, 
temperature of the samples implanted at room temperature increased to about $50^{\circ} \mathrm{C}$. To investigate the effect of substrate temperature during ion bombardment, some samples were implanted at $350^{\circ} \mathrm{C}$ and some at $600^{\circ} \mathrm{C}$.

Some samples were vacuum annealed in a computer controlled Webb graphite furnace for different periods at temperatures ranging from 900 up to $1600^{\circ} \mathrm{C}$. The base pressure prior to annealing was in the range $10^{-6}-10^{-7}$ mbar. During annealing, the pressure sharply increased to a maximum of $5 \times 10^{-5}$ mbar and then decreased to the $10^{-6}$ mbar range.

\section{RESULTS AND DISCUSSION}

Heavy ion bombardment of the covalent-bonded ceramic $\mathrm{SiC}$ at room temperature causes the substrate to become amorphous at relatively low doses [7]. However, it is generally accepted that implanting $\mathrm{SiC}$ at $350^{\circ} \mathrm{C}$ and at $600^{\circ} \mathrm{C}$ results in the $\mathrm{SiC}$ remaining crystalline albeit with many point defects present $[7,8]$.

Figure 1. An in-lens SEM image of $6 \mathrm{H}-\mathrm{SiC}$ bombarded by $360 \mathrm{keV} \mathrm{Ag}^{+}$ions at room temperature to a fluence of $2 \times 10^{16} \mathrm{~cm}^{-2}$. The implanted sample was vacuum annealed at $900^{\circ} \mathrm{C}$ for $10 \mathrm{~h}$ and again for $20 \mathrm{~h}$ at $1200^{\circ} \mathrm{C}$. The sample was cut into two parts and glued together to form a sandwich. The image is a cross-section of the sandwiched sample. The middle black band is the glue that held the two samples together.

Figure 1 shows an in-lens SEM image of $6 \mathrm{H}-\mathrm{SiC}$ bombarded by $360 \mathrm{keV} \mathrm{Ag}^{+}$ions at room temperature. After ion bombardment, the samples were first vacuum annealed for $10 \mathrm{~h}$ at $900^{\circ} \mathrm{C}$ and then again for $20 \mathrm{~h}$ at $1200^{\circ} \mathrm{C}$. The reason for this double choice of 
annealing conditions was to determine the effect of silver transport in a polycrystalline $\mathrm{SiC}$ substrate and not in amorphous $\mathrm{SiC}$. Room temperature implantation of heavy ions (such as $\mathrm{Ag}$ ) results in the complete amorphization of the implanted region of $\mathrm{SiC}$. It is known $[9,10]$ that annealing at $900^{\circ} \mathrm{C}$ (which is below the melting point of silver) results in the recrystallization of the bombardment-induced a-SiC. Ag starts to diffuse in polycrystalline $\mathrm{SiC}$ only at about $1200^{\circ} \mathrm{C}[11,12]$. Three features in Figure 1 are of interest for this paper. There is a whitish band approximately $150 \mathrm{~nm}$ wide from the surface. The projected range of $360 \mathrm{keV} \mathrm{Ag}{ }^{+}$ions in $6 \mathrm{H}-\mathrm{SiC}$ with density of $3.215 \mathrm{~g} / \mathrm{cm}^{3}$ [13] is $110 \mathrm{~nm}$ and the projected range straggling $27 \mathrm{~nm}$ [14]. Consequently, the width of the white band corresponds to the width of the implanted layer in the SiC. The uniformity of the colour across the layer is an indication that the white band represents the damaged layer. This layer was originally the bombardment-induced amorphized layer which was recrystallized by the annealing steps as discussed above. However, our channelling studies [15 - 17] show that the layer still contains damage after annealing - also visible in Figure 1 as the white band. This is in agreement with other observations of defect detection in $\mathrm{SiC}$ with an in-lens SEM [3,4]. Another feature in Figure 1 is the small bright spheres in the implanted layers. From a comparison of the SEM and backscattering images, it followed that these spheres were silver precipitates resulting from the diffusion and conglomeration of the implanted silver atoms during the annealing process. This conglomeration of implanted species in $6 \mathrm{H}-\mathrm{SiC}$ into nanocrystals after annealing above $1200^{\circ} \mathrm{C}$ has been previously observed for other elemental implants - see [9] for a review. These nanocrystals were only observed after high temperature implantation (typically $700^{\circ} \mathrm{C}$ to retain crystallinity of the substrate) and subsequent annealing at $1600^{\circ} \mathrm{C}$. The majority of these precipitates in Figure 1 are also in the region of the projected range of the implanted silver which confirms our premise that they are Ag nanocrystals. EBSD (Electron Back Scattered Diffraction) measurements performed on crystallites showed them to be $3 \mathrm{C}-\mathrm{SiC}$. Due to the low solubility of $\mathrm{Ag}$ in $\mathrm{SiC}$, the silver atoms segregate out of $\mathrm{SiC}$ crystallites. The precipitates are probably tetrahedrally bounded by $\{111\}$ planes. The reason being that the $\{111\}$ plane has the lowest surface energy [9]. The final feature of Figure 1 is the unevenness of the implanted surfaces. After implantation, the implanted surfaces were completely featureless because of the amorphization of the $6 \mathrm{H}-\mathrm{SiC}$ by silver ion bombardment at room temperature $[15,16]$. Vacuum annealing at temperatures above $800^{\circ} \mathrm{C}$ caused recrystallization of the amorphous $\mathrm{SiC}-$ see Figure 2. RBS/channelling investigations showed that there is gradual (depending on the annealing temperature) epitaxial regrowth taking place from the amorphous-crystalline interface [16]. In Figure 2 , numerous small crystallites are visible with random orientation indicating that the crystalline substrate played no role in the recrystallization process.

Our RBS/channelling studies [17] showed that in contrast to room temperature implantation, silver ion bombardment at $600^{\circ} \mathrm{C}$ resulted in the $6 \mathrm{H}-\mathrm{SiC}$ remaining single crystalline albeit with point defects due to the presence of the implanted foreign silver atoms. RBS measurements [16, 17] indicated that there is also no transport / diffusion of the implanted $\mathrm{Ag}$ in single crystalline $\mathrm{SiC}$ even at higher annealing temperatures (i.e. $1500^{\circ} \mathrm{C}$ ) in contrast to that in polycrystalline $\mathrm{SiC}$ as shown in Figures 1 and 2 . In Figure 


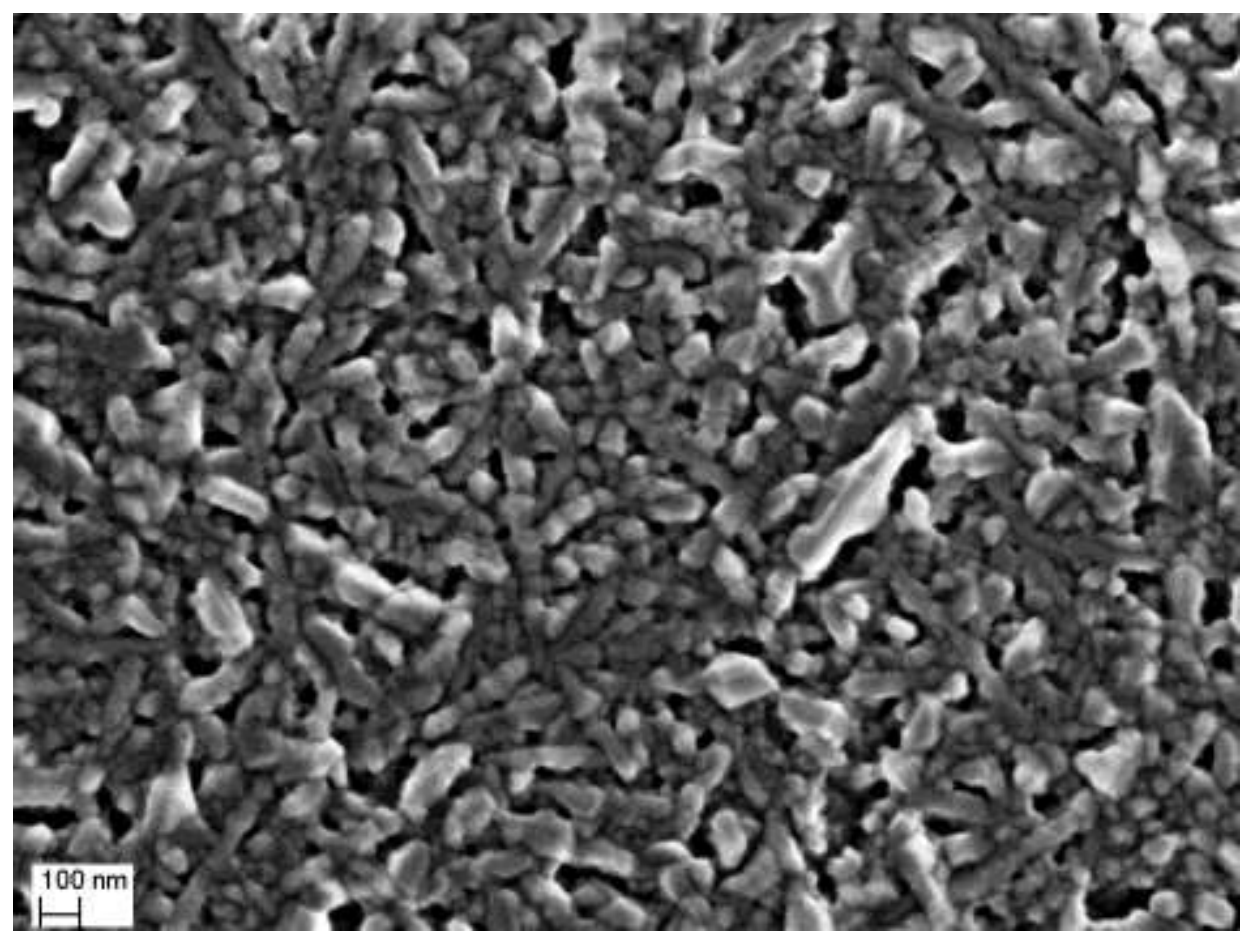

Figure 2. An in-lens SEM image of a $6 \mathrm{H}-\mathrm{SiC}$ surface bombarded by $360 \mathrm{keV} \mathrm{Ag}^{+}$ions at room temperature and then vacuum annealed at $900^{\circ} \mathrm{C}$ for $10 \mathrm{~h}$ and again for $20 \mathrm{~h}$ at $1200^{\circ} \mathrm{C}$. The image show that the annealed surface consists of crystallites with random orientation.

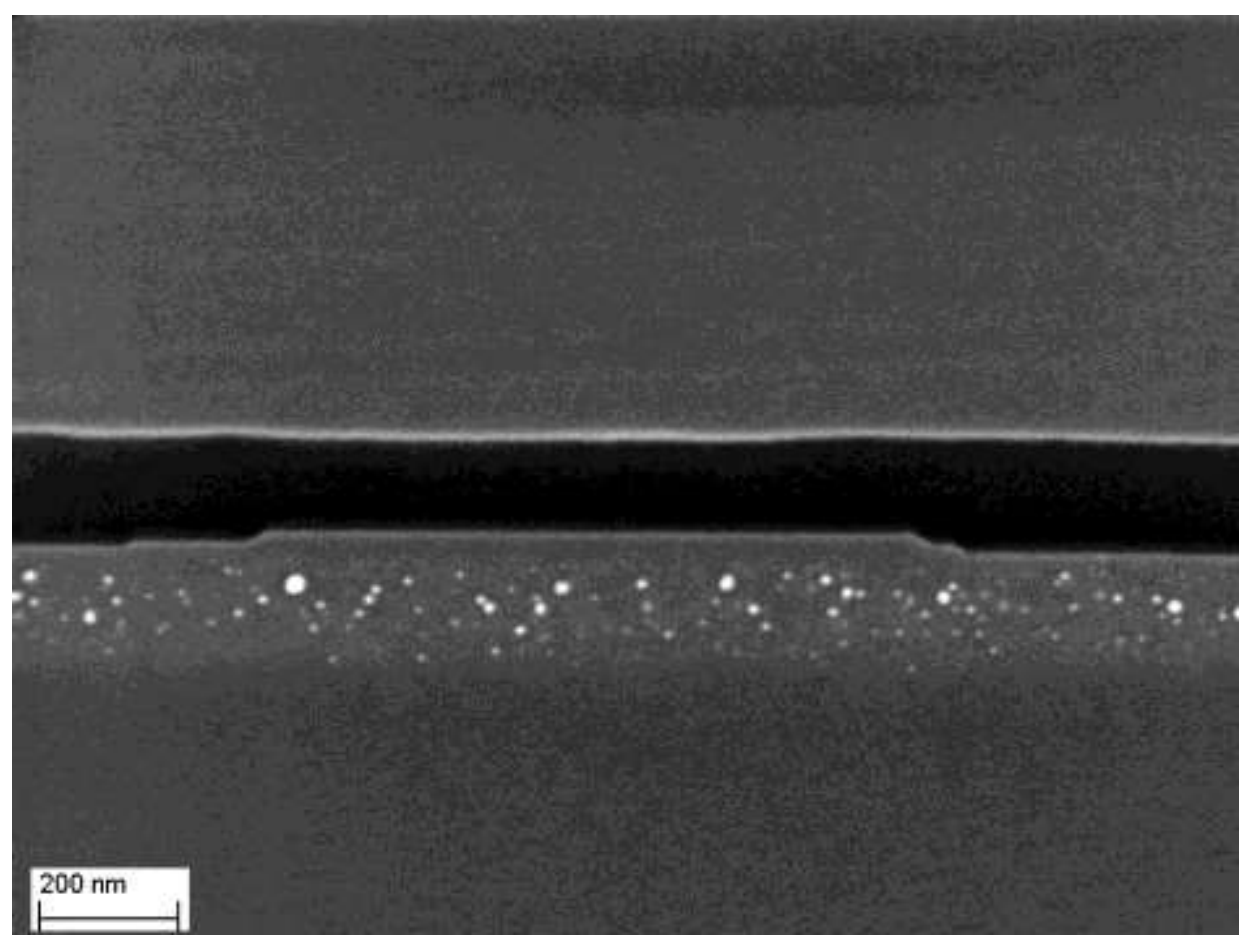

Figure 3. An in-lens SEM image of a cross-section surface of a sandwiched sample of $6 \mathrm{H}-\mathrm{SiC}$ bombarded by $360 \mathrm{keV} \mathrm{Ag}$ ions at $600^{\circ} \mathrm{C}$ to a fluence of $2 \times 10^{16} \mathrm{~cm}^{-2}$ and virgin $6 \mathrm{H}-\mathrm{SiC}$ substrate (at the top). The implanted sample was vacuum annealed at $1500^{\circ} \mathrm{C}$ for $6 \mathrm{~h}$. After annealing the samples were glued together to form a sandwich. The middle black band is the glue that held the two samples together. 
3, a cross-sectional SEM image of a $600^{\circ} \mathrm{C}$ Ag implanted $6 \mathrm{H}-\mathrm{SiC}$ sample annealed at $1500^{\circ} \mathrm{C}$ for $6 \mathrm{~h}$ shows again small silver precipitates in the $6 \mathrm{H}-\mathrm{SiC}$ which precipitated during the annealing process. However, in contrast to the room temperature implanted case, these precipitates are more evenly spaced throughout the whitish implanted band indicating that the crystalline structure did not allow the formation of large openings in the $\mathrm{SiC}$ for the conglomeration/precipitation of $\mathrm{Ag}$ into relatively large (as was the case for the room temperature implanted samples which were amorphous after the ion bombardment) silver precipitates. These smaller and more evenly spread Ag precipitates in the single crystalline $6 \mathrm{H}-\mathrm{SiC}$ compared to the larger $\mathrm{Ag}$ precipitates in the polycrystalline $\mathrm{SiC}$ layer shown in Figures 1 and 2 can be understood from the mechanisms of their formations. TEM investigations [18] of Ge and Er high temperature implanted nanocrystals showed that the Ge and Er atoms segregated to dislocation cores to form the nanoprecipitates. One can expect the same mechanism for the silver precipitates. Again the implanted $6 \mathrm{H}-\mathrm{SiC}$ surface (see Figure 3) does not appear completely flat. After the $600^{\circ} \mathrm{C}$ implantation process, SEM images of the implanted surfaces were featureless as is expected of a flat single crystal surface. The uneven surface in Figure 3 is due to step bunching occurring during the high temperature $\left(1500^{\circ} \mathrm{C}\right)$ vacuum annealing $[3,19]$. Step bunching is the conglomeration of steps and the formation of multiple-height steps on crystal surfaces. Step bunching also occurs during epitaxial growth which is a step-flow mechanism [20]. Since crystal growth and thermal etching are essentially similar

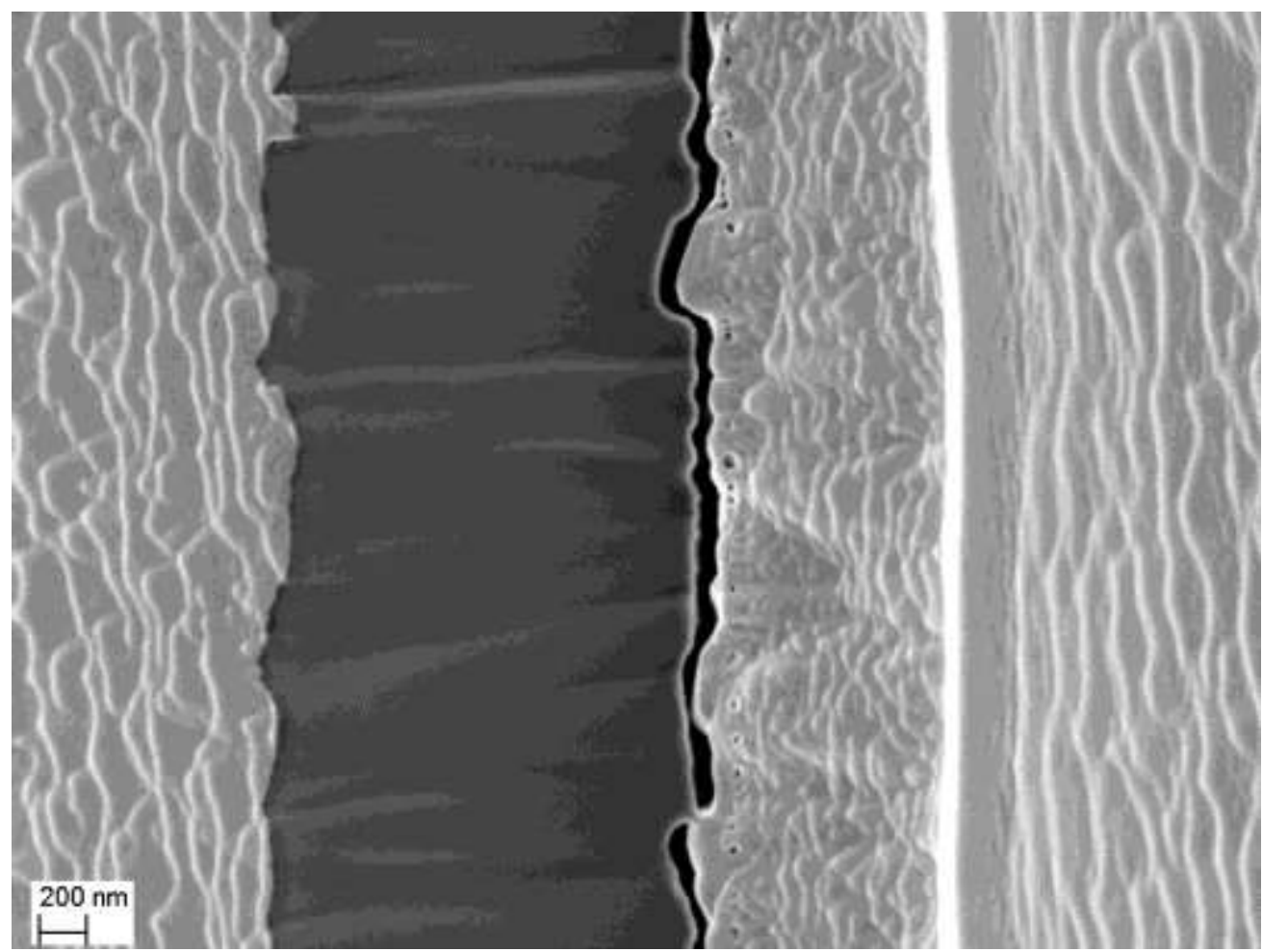

Figure 4. An in-lens SEM image of a cross-section surface of a sandwiched sample of $6 \mathrm{H}-\mathrm{SiC}$ bombarded by $360 \mathrm{keV} \mathrm{I}$ ions at room temperature to a fluence of $2 \times 10^{16} \mathrm{~cm}^{-2}$ and a virgin $6 \mathrm{H}-\mathrm{SiC}$ substrate (on the left). The implanted sample was vacuum annealed at $1600^{\circ} \mathrm{C}$ for $5 \mathrm{~h}$. After annealing the samples were glued together to form a sandwich. The middle black band is the glue that held the two samples together. During the mechanical polishing process the bond broke between the glue and the implanted sample surface. 
processes at the two extreme regimes, step bunching is used as evidence of thermal etching on single crystal surfaces $[3,19]$. Thermal etching is the preferential sublimation of some crystal surfaces due to differences in the surface binding energies of the different surfaces. The formation of $\mathrm{SiC}$ "islands" due to step bunching as depicted in Figures 3 will have a detrimental effect on RBS depth profiling. The silver RBS profile will broaden making it appear as if the silver is diffusing more than it might in reality.

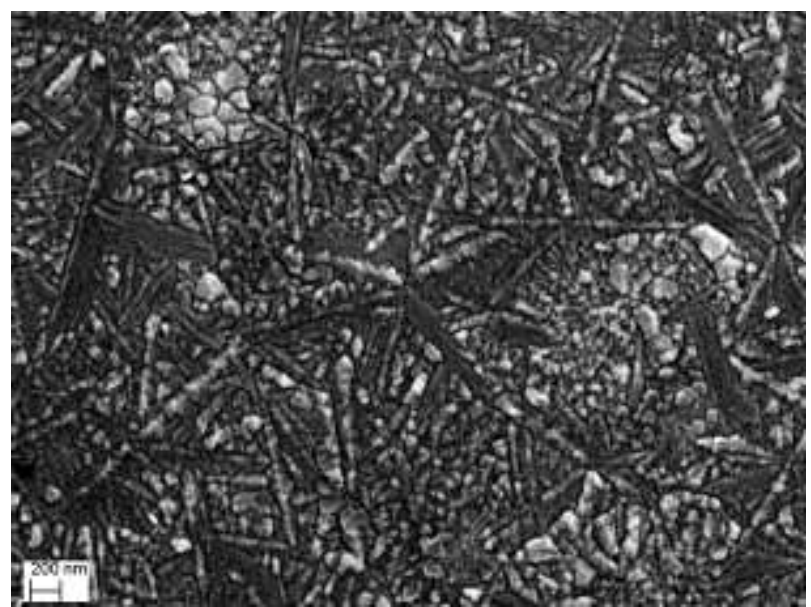

(a)

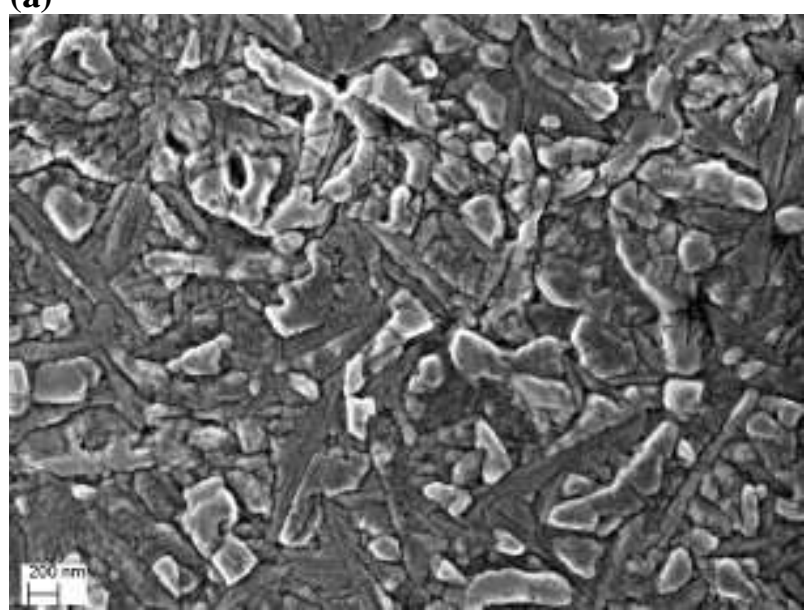

(c)

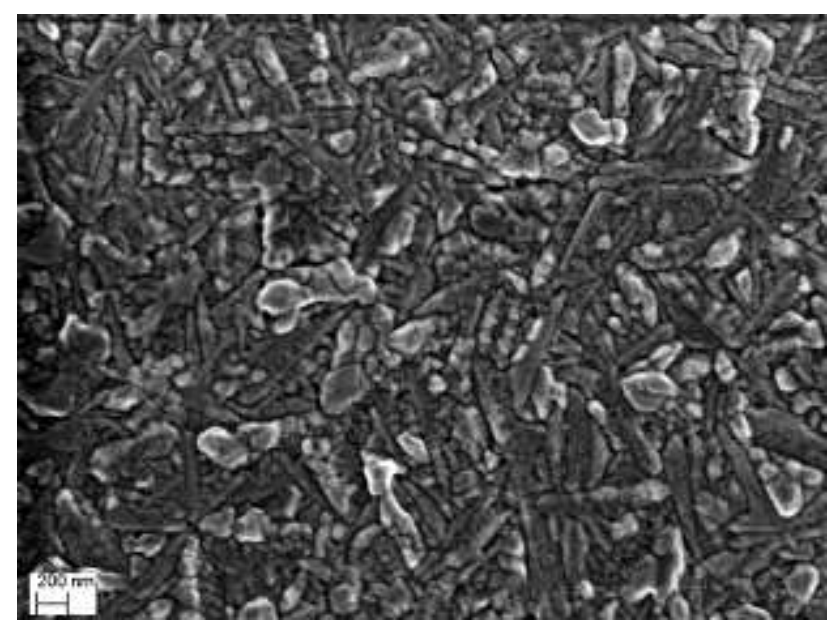

(b)

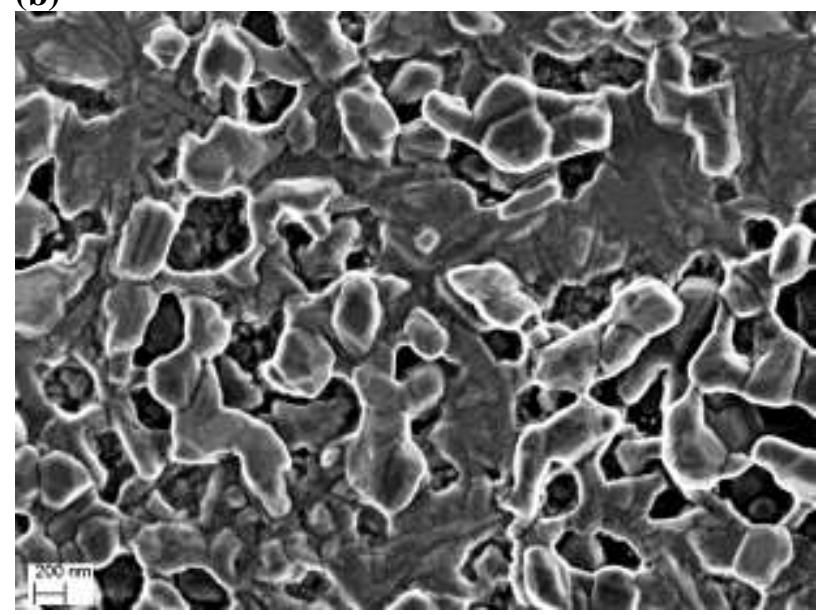

(d)

Figure 5. In-lens SEM images of room temperature iodine implanted $6 \mathrm{H}-\mathrm{SiC}$ surfaces after vacuum annealing at $1100^{\circ} \mathrm{C}$ for (a) $5 \mathrm{~h}$, (b) $60 \mathrm{~h}$, and after vacuum annealing at $1200^{\circ} \mathrm{C}$ for (c) $5 \mathrm{~h}$, and (d) $60 \mathrm{~h}$.

Implanting $6 \mathrm{H}-\mathrm{SiC}$ with reactive ions such as iodine leads to differences in the microstructure of the $6 \mathrm{H}-\mathrm{SiC}$ compared to the inert Ag implantation. Figure 4 shows an in-lens SEM image of a cross-section of room temperature $\mathrm{I}^{+}$implanted $6 \mathrm{H}-\mathrm{SiC}$ sample vacuum annealed afterwards at $1600^{\circ} \mathrm{C}$ for $5 \mathrm{~h}$. The higher annealing temperature for the iodine implanted samples compared to the silver samples was chosen to compare our results to other reported nanoprecipitates in $6 \mathrm{H}-$ $\mathrm{SiC}$ as summarised in reference [9]. Holes are visible at about the projected range of the 360 $\mathrm{keV}$ iodine ions in $\mathrm{SiC}$. The origin of these holes is similar to the Ag precipitates seen in Figures 1 and 3. In the SEM image in Figure 5, the holes are dark indicating that there is no or little iodine left in these openings. The reason for the absence of iodine in these voids, is related to the 
thermal and sputter properties of iodine. Iodine is an element which volatizes at room temperature due to its low heat of vaporization of $41.57 \mathrm{~kJ} / \mathrm{mol}$. During the final surface smoothing process of low energy $\mathrm{Ar}^{+}$ion bombardment, the temperature of the substrate increased substantially above room temperature allowing the elemental iodine in the openings to sublimate. Furthermore, iodine sputters more easily than SiC. Therefore, it will also be preferentially eroded from the holes.

Another difference with the silver implanted samples is the enhanced topography development on the $6 \mathrm{H}-\mathrm{SiC}$ surface. In Figure 5, SEM images of room temperature $\mathrm{I}^{+}$ implanted $6 \mathrm{H}-\mathrm{SiC}$ samples vacuum annealed at $1100^{\circ} \mathrm{C}$ and at $1200^{\circ} \mathrm{C}$ for two different annealing times of $5 \mathrm{~h}$ and $60 \mathrm{~h}$, show the development of the surface topography from the flat featureless surface of an as-implanted surface. For the $1100^{\circ} \mathrm{C} 5 \mathrm{~h}$ annealed sample, the surface consists of many dendritic crystals stretching radially out from a point - see Figure 5(a). There appears to be sections composed of closely packed small crystals and regions in between the crystallites where the surface seems flat and featureless - probably amorphous regions. The crystallization on the surface appears to be independent of the underlying crystalline region as the crystals grew randomly with no preferred orientation. This indicates that the crystal growth was not epitaxially from the crystalline substrate but originated from small recrystallized seed crystals within the bombardment-induced amorphized layer. Some of the crystallites are protruding more than others in line with the flow-step model of crystal growth of Burton et al. [20] and Hirsch and Pound [21]. As expected from this model, some surface crystals grew parasitically larger with annealing time. After annealing for 60 hours (see Figure 5(b)), the featureless regions had disappeared. The sample surfaces remained fairly continuous at this temperature with no clear indications of cavities or holes forming on the surface. At $1200^{\circ} \mathrm{C}$, the crystallites were larger than to those formed at $1100^{\circ} \mathrm{C}$. At this temperature, cavities appeared. Even for the $5 \mathrm{~h}$ annealed samples (see Figure 5(c)), the surface appears to be less continuous and cavities could be seen on the surface. The samples annealed for $5 \mathrm{~h}$ still had dendritic crystal starting from a point. For longer annealing times, the sizes of the crystals became larger, overlapping with each other, causing the "growth" points to become less noticeable. The number and size of the cavities increased with annealing time. The crystallites are facetted. After annealing for $60 \mathrm{~h}$ many large cavities were formed - see Figure 5(d). These trends in increasing annealing temperatures and increasing annealing times continued to eventually result in the severe surface topography evident in Figure 4. This severe topography development follows from a step-flow epitaxial process where some crystal surfaces, i.e. the ones with the high surface energies, grow preferentially to expose more low energy surface areas in agreement with Wulff's Law [22].

The logical explanation for the difference in the microstructure between silver and iodine implanted $6 \mathrm{H}-\mathrm{SiC}$ is the difference in the chemistry of the implanting species with the substrate. No known compound is formed between $\mathrm{Ag}$ and $\mathrm{Si}, \mathrm{C}$ or $\mathrm{SiC}$. It is known [23, 24] that iodine reacts with $\mathrm{Si}$ to form $\mathrm{SiI}_{4}$ which reacts further with silicon at higher temperatures to form $\mathrm{SiI}_{2}$. However, $\mathrm{SiI}_{2}$ is also known to be unstable at high temperatures (above $1000^{\circ} \mathrm{C}$ ). No other compound between iodine and $\mathrm{C}$ or $\mathrm{SiC}$ has been reported. The difference in the microstructure suggests that there might be a possibility of such compounds forming, whether stable or unstable. EDX (Energy-Dispersive X-ray spectroscopy) done on our iodine implanted samples did not detect any iodine. This is not surprising as the excitation/analysis volume and depth of EDX are 
orders of magnitude larger than the implanted layer depth and volume.

Furthermore, there have been reports that iodine aids in the growth 3C-SiC. Ramesh et al. [25] reported that pure 3C-SiC is obtained when heating $\mathrm{Si}$ and activated carbon powder in an iodine atmosphere in a commercial microwave oven. This is reminiscent of another 3C-SiC growth process using another halogen element $\mathrm{Cl}$. During the growth of stoichiometric polycrystalline $3 \mathrm{C}$ CVD SiC using a $\mathrm{Cl}$ containing precursor methyltrichlorosilane $\left(\mathrm{CH}_{3} \mathrm{SiCl}_{3}\right)$ a hydrogen mixture $\mathrm{HCl}$ is formed. Papasouliotis et al [26] found that the presence of $\mathrm{HCl}$ has several benefits for CVD SiC, inter alia the uniformity of the $\mathrm{SiC}$ and a complete suppression of free $\mathrm{Si}$. The model of I conducivity to grow stoichiometric SiC is doubted by Pedersen et al [27]. Pedersen quoted that the average bond enthalpies at $25^{\circ} \mathrm{C}$ for the $\mathrm{Si}-\mathrm{Si}, \mathrm{Si}-\mathrm{Cl}$, and $\mathrm{Si}-\mathrm{I}$ bonds are 226, 400, $234 \mathrm{~kJ} \mathrm{~mol}^{-1}$, respectively. According to Pedersen, the best choice is chlorine since the iodine atom is too large and a too weak bond to $\mathrm{Si}$.

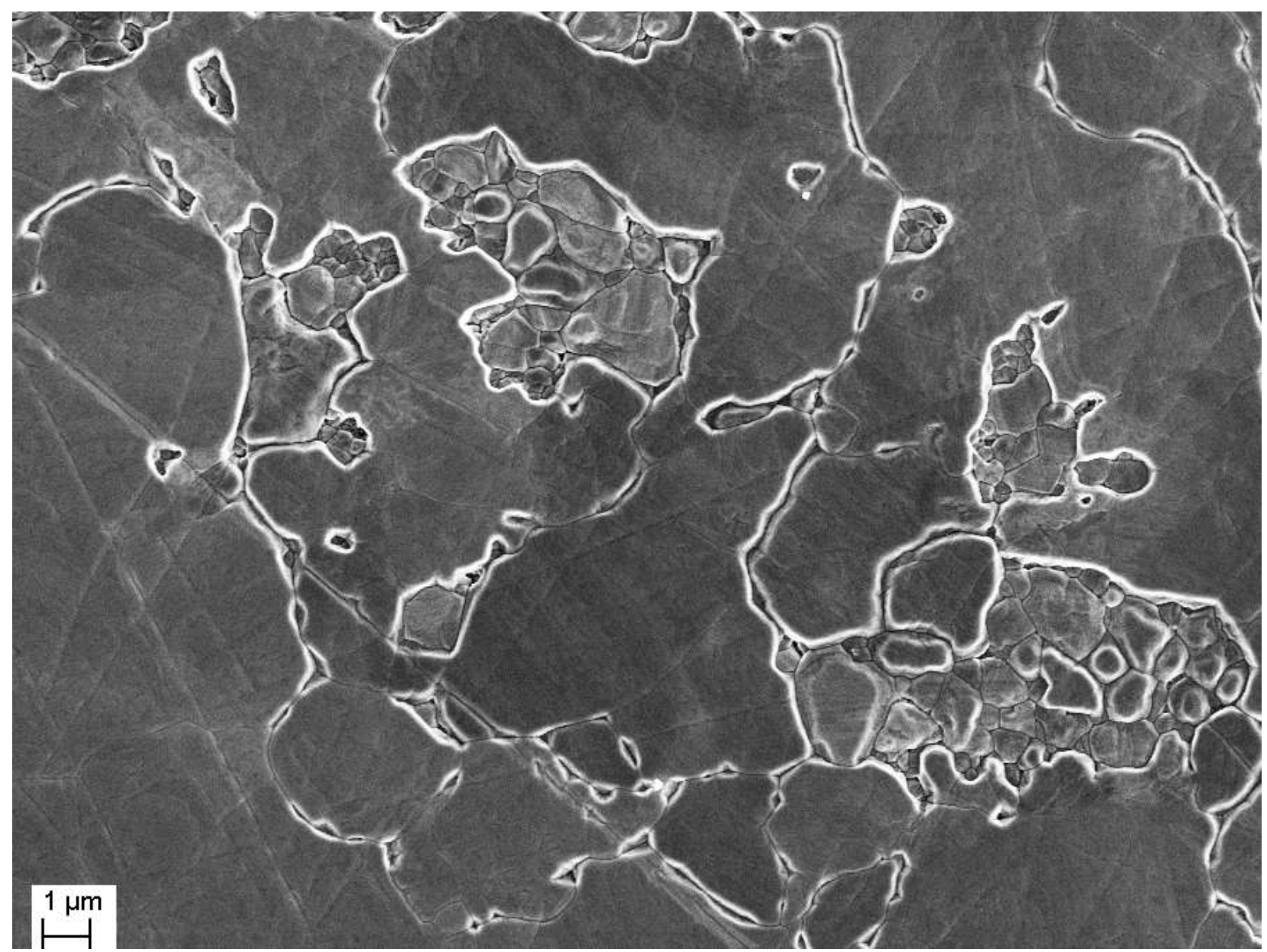

Figure 6. An in-lens SEM image of $350^{\circ} \mathrm{C} \mathrm{Xe}^{+}$implanted polycrystalline $\mathrm{SiC}$ and then vacuum annealed at at $1200^{\circ} \mathrm{C}$ for a total of $40 \mathrm{~h}$ consisting of 4 annealing stages of $5 \mathrm{~h}+5 \mathrm{~h}+10 \mathrm{~h}+20 \mathrm{~h}$.

Heavy ion implantation of polycrystalline $\mathrm{SiC}$ at room temperature amorphizes the substrate similarly as in the case of $6 \mathrm{H}-\mathrm{SiC}$, to render a flat featureless surface. However, implanting at even $350^{\circ} \mathrm{C}$ causes the implanted region to remain polycrystalline. When vacuum annealing these samples, changes appear between implanted and unimplanted SiC similarly treated. In 
Figure 6, a polycrystalline $\mathrm{SiC}$ substrate is shown which was implanted with $360 \mathrm{keV} \mathrm{Xe}^{+}$ions and subsequently vacuum annealed at $1200^{\circ} \mathrm{C}$ for a total of $40 \mathrm{~h}$ consisting of 4 annealing stages of $5 \mathrm{~h}+5 \mathrm{~h}+10 \mathrm{~h}+20 \mathrm{~h}$. In Figure 7, an unimplanted part of the same (implanted) polycrystalline $\mathrm{SiC}$ sample is shown. On both SEM images, scratch marks from the factory polishing process are visible as well as the grains boundaries of the crystallites. Many of the grain boundaries of the implanted sample are pronouncedly etched (i.e. grain boundary grooving) because of thermal etching occurring during the vacuum annealing. This opening up of high angle boundaries by thermal etching is due to increased stress/strain caused by the large implanted atoms in interstitial positions. The surface regions of some of the grains were severely etched. In contrast, limited thermal etching occurred at the grain boundaries of the unimplanted sample. The surface regions of the grains were also not etched to the same extent as in the implanted sample. The differences are due to the radiation damage in the SiC introduced by the bombarding xenon ions. The extent of the radiation damage in each crystallite depends on the orientation of the crystallite, i.e. the damage will be deeper in crystallites with on-axis orientation allowing channelling to take place. This effect coupled with difference between the surface energies of different crystal orientations caused increased thermal etching to occur in those regions with high surface energies in order to expose lower surface energy areas thereby lowering the total energy of the system in agreement with Wulff's Law [22].

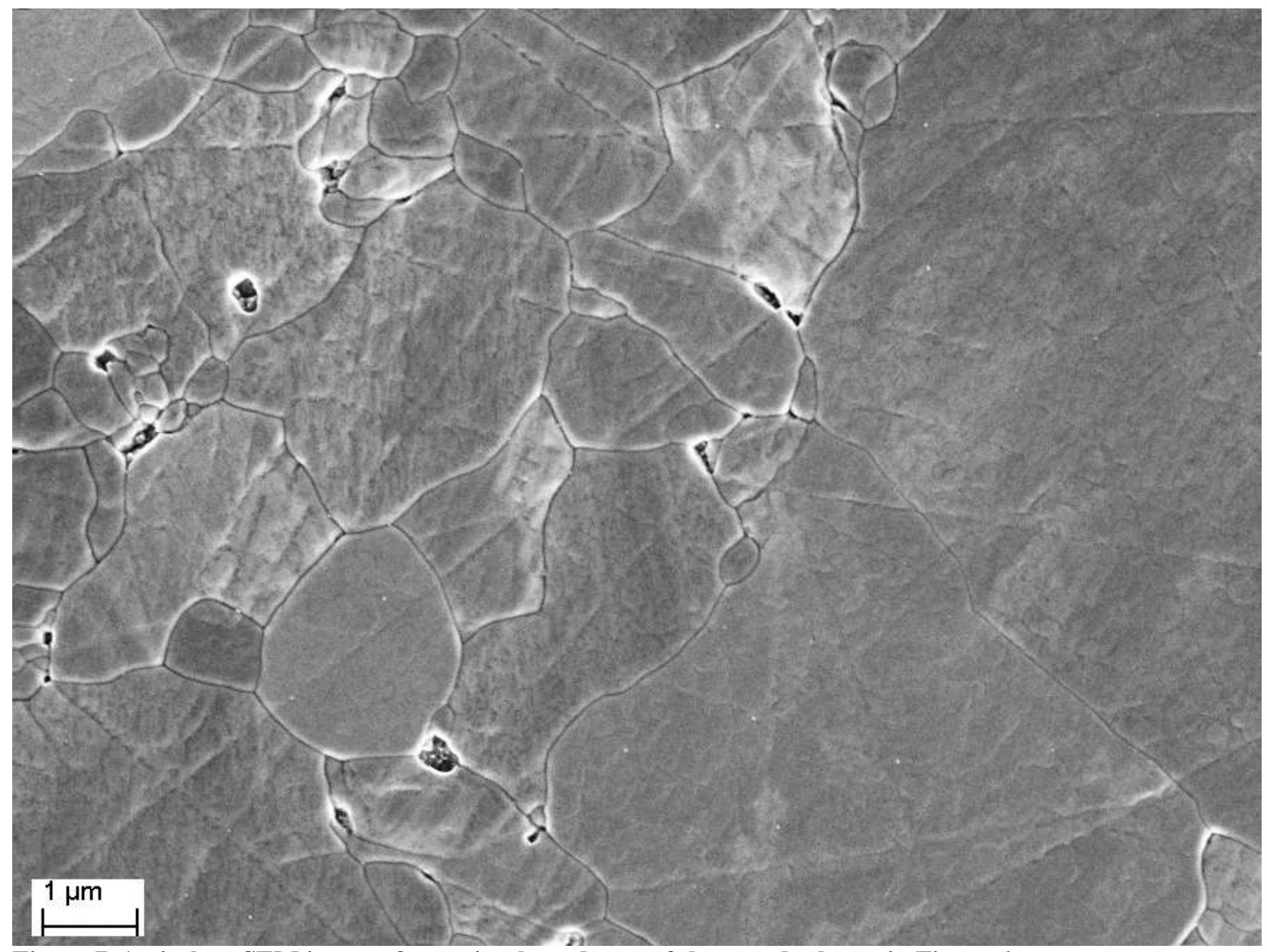

Figure 7. An in-lens SEM image of an unimplanted part of the sample shown in Figure 6. 


\section{SUMMARY}

Modern high resolution SEMs with in-lens detector systems are capable of detecting crystal defects which are traditionally only possible to detect using TEM with its demanding sample preparation steps. This paper shows how this property can be used to observe the implanted layer and its thickness with SEM with considerably less effort in sample preparation than with TEM.

Annealing of $\mathrm{Ag}$ implanted $\mathrm{SiC}$ showed that the metastable solid solute of implanted $\mathrm{Ag}$ atoms in $\mathrm{SiC}$ is transformed into $\mathrm{SiC}$ with $\mathrm{Ag}$ precipitates. There are differences in the Ag conglomeration between room temperature and elevated temperature implanted $6 \mathrm{H}-$ $\mathrm{SiC}$. The voids (bubbles) in the elevated temperature implanted layer are generally smaller and are spread throughout the implanted layer. This is due to the difference in the implant precipitation mechanisms between the two substrates. In the case of the elevated temperature implanted $\mathrm{SiC}$ with its retained crystallinity, the implanted material precipitates at dislocation cores. In polycrystalline $\mathrm{SiC}$, the precipitation occurs between grains bordering with low energy surfaces.

The microstructure of $6 \mathrm{H}-\mathrm{SiC}$ implanted with the iodine ions and then annealed are different to $\mathrm{Ag}$ implanted $6 \mathrm{H}-\mathrm{SiC}$. Step bunching became evident in the $1600^{\circ} \mathrm{C}$ annealed samples due to the occurrence of thermal etching. At lower annealing temperatures, dendritic crystallites grow from growth points radially out until they start overlapping with one another. The crystallites are larger than in the case of Ag implantation with large openings; some even reaching the unimplanted bulk indicating a step-flow epitaxial process where some crystal surfaces, i.e. the ones with the high surface energies, grow preferentially to expose more low energy surface areas.

Implanting and annealing polycrystalline $\mathrm{SiC}$ with $\mathrm{Xe}$ ions at elevated $\left(350^{\circ} \mathrm{C}\right)$ temperatures allows the $\mathrm{SiC}$ to remain polycrystalline. Annealing at $1200^{\circ} \mathrm{C}$ caused grain boundary grooving to occur at the high angle boundaries. This grain boundary grooving was due to increased stress/strain caused by the large implanted atoms in interstitial positions. Damage due to channelling (or non-channelling) in the different crystallites resulted also in differences in thermal etching in the crystallites.

\section{REFERENCES}

1. J.B. Malherbe, Critical Rev. Solid State Mater. Sci. 19 (1994) 129.

2. O. Auciello and R. Kelly, Ion Bombardment Modification of Surfaces, Elsevier, Amsterdam 1984.

3. N.G. van der Berg, J.B. Malherbe, A.J. Botha and E. Friedland, Appl. Surf. Sci. 258 (2012) 5561.

4. N.G. van der Berg, J.B. Malherbe, A.J. Botha, E. Friedland and W.A. Jesser, Surf. Interface Anal. 42 (2009) 1156 -1159; ibid 1377.

5. J.B. Malherbe, E. Friedland, N.G. van der Berg, Nucl. Instr. Methods Phys. Res. B266 (2008) 1373. 
6. E. Friedland, N.G. van der Berg, J.B. Malherbe, E. Wendler \& W. Wesch, J. Nucl. Mater. 425 (2012) 205.

7. W. Wesch, A. Heft, E. Wendler, T. Bachmann, E. Glaser, Nucl. Instrum. Methods Phys. Res. B 96 (1995) 335.

8. E. Wendler, A. Heft, W. Wesch Nucl. Instrum._Methods Phys. Res. B 141 (1998) 105.

9. J.B. Malherbe, J. Phys. D Appl. Phys. (2013) To be published.

10. L.L. Snead and S.J. Zinkle, Nucl. Instrum. Meth. Phys. Res. B 191 (2002) 497.

11. E.K.H. Friedland, J.B. Malherbe, N.G. van der Berg, T. Hlatshwayo, A.J. Botha, E. Wendler \& W. Wesch, J. Nucl. Mater. 389 (2009) 326.

12. E. Friedland, N.G. van der Berg, J.B. Malherbe, J.J. Hancke, J.R.N. Barry, E. Wendler \& W. Wesch, J. Nucl. Mater. 410 (2011) 24.

13. L.L. Snead, T. Nozawa, Y. Katoh, T.-S. Byun, S. Kondo and D.A. Petti, J. Nucl. Mater. 371 (2007) 329.

14. J.F. Ziegler, M.D. Ziegler and J.P. Biersack, SRIM-2006, http://srim.org/, 5 Nov. 2006..

15. E.K.H. Friedland, J.B. Malherbe, N.G. van der Berg, T. Hlatshwayo, A.J. Botha, E. Wendler \& W. Wesch, J. Nucl. Mater. 389 (2009) 326.

16. T.T. Hlatshwayo, J.B. Malherbe, N.G. van der Berg, L.C. Prinsloo, A.J. Botha, E. Wendler and W. Wesch, Nucl. Instrum. Methods Phys. Res. B 274 (2012) 120.

17. T.T. Hlatshwayo, J.B. Malherbe, N.G. van der Berg, A.J. Botha and P. Chakraborty, Nucl. Instrum. Methods Phys. Res. B 273 (2012) 61.

18. U. Kaiser, D.A. Muller, J.L. Grazul, A. Chuvilin and M. Kawasaki, Nature Mater. 1 (2002) 102.

19. N.G. van der Berg, J.B. Malherbe, A.J. Botha and E. Friedland, Surf. Interface Anal. Submitted for publication.

20. W. K Burton, N Cabrera and F C. Frank, Phil. Trans. Roy. Soc. 243A (1931) 299.

21. J.P. Hirth and G.M. Pound, J. Phys. Chem. 64 (1960) 619.

22. G. Wulff, Z. Krist. 34 (1901) 449.

23. T.F. Ciszek, .H. Wang. M.R. Page, R.E. Bauer, and M.D. Landry IEEE (2002).

24. T.H. Wang and T.F. Ciszek, J. Electrochem. Soc. 147 (2000) 1945.

25. P.D. Ramesh, B. Vaidhyanathan, M. Ganguli and K.J. Rao, J. Mater. Res. 9 (1994) 3025.

26. G.D. Papasouliotis and S.V. Sotirchos, J. Mater. Res. 14 (1999) 3397.

27. H. Pedersen, S. Leone, A. Henry, V. Darakchieva and E. Janzén, Surf. Coat. Tech. 201 (2007) 8931. 